DOI: $10.20472 / B M .2016 .4 .2 .003$

\title{
THE PURCHASE DECISION PROCESS WITHIN ALGERIAN FAMILIES: SHADOWS AND QUALITATIVE ENLIGHTENING.
}

\section{NADIRA BESSOUH, ALI IZNASNI}

\begin{abstract}
:
This article aims to contribute to understanding the buying behavior of the Algerian family. Its main objective is to determine the roles and influences of the two parents in making a purchase decision, along with the most influencing variables. To do that, a field study was conducted on a sample of 200 households. The results of this study would enable managers of points of sales to better understand the distribution of roles, in order to establish an adequate marketing strategy (targeting and positioning) and thus adapt the design of products to the needs of those who have the greatest influence on the purchase decision.
\end{abstract}

\section{Keywords:}

Consumer behavior, Purchase decision, Involvement, Algerian family.

\section{Authors:}

NADIRA BESSOUH, The Preparatory School of Economics, Business Studies and Management Science, Tlemcen- Algeria, ALGERIA, Email: bessouh_nadira@yahoo.fr ALI IZNASNI, The Preparatory School of Economics, Business Studies and Management Science, Tlemcen- Algeria, ALGERIA, Email: aiznasniali@hotmail.fr

\section{Citation:}

NADIRA BESSOUH, ALI IZNASNI (2016). The Purchase Decision Process Within Algerian Families: Shadows and Qualitative Enlightening.. International Journal of Business and Management, Vol. IV(2), pp. 33-41., 10.20472/BM.2016.4.2.003 


\section{Introduction}

Algerians consider that the family is very important. Over the last thirty years, its contours have been through many changes, such as reduction in household size and number of children, significant increase in the number of active women, fathers getting more involved in the parenting activities, beside the vagaries of family and professional life. All these parameters are fundamental matters in making a purchase decision at home. Today, manufacturers and distributors generally anticipate the global market demand mainly from the family purchase decisions (Tammy and al, 2000).

In this context, the present research attempts to study and analyze the different purchases which are made by the Algerian household. Our research focused on supplying a home with electronic equipment and electrical appliances. Nowadays, this issue represents a particular area of investigation. Several studies were carried out by Davis and Rigaux (1974), Beatty and Talpade (1994), Belch and Willis (2002), where they used the above mentioned products to highlight the interaction of family members with each other, during the buying process. This research was carried out within this framework of thought. It aimed at providing some answers to the following research question: What are the respective roles of family members involved in the purchase of home appliances?

This research intends to highlight the role of each family member in the purchase of a household product. To investigate this problem, the following two assumptions were considered:

H1: The influence and role of one of the family members differ, depending on the interest given to the product.

H2: Perceptions of roles within households for the purchase of household appliances are different from one agglomeration zone to another.

\section{The importance of studying the family purchasing decision}

Family purchasing behavior is a quite particular subject. It is very complex because it is difficult to observe the parents within the family (Gharbi, 1998). Moreover, purchasing decisions within the family are characterized by interdependence, which implies an internal managing of various participations; this task is often difficult and arbitrary (Cherfi, 2011). The family purchasing behavior is characterized by shared resources and mutual subordination of needs between the family members. Therefore, there is a multiplicity of needs, but also a convergence of interests for the good of the group or the family, despite the existence of interests and needs specific to each one (Desingly, 1993).

Regarding the various factors that may cause variation in the impact on the family buying process, one can cite first the characteristics of each family member (status), his/her motivations, perceptions, attitudes ... Then come the family characteristics such as size, social class, the contributions of each member to family income, income level and education level of parents. Finally, the involvement of the mother, father and child in the purchase process comes last (Watne and Brennan, 2011). 
All these variables make the study of the purchasing process of the family dyad very complex; there are also other environmental factors that may influence implicitly or explicitly the purchasing behavior (culture, religion, customs, ... etc).

In their work, Houdert and Antonides (1997) showed that the roles of family members change with the type of products to be bought and with the steps in the purchase process as well. In other studies, Kaur and Mudury (2010) found that the child is getting more and more actively involved in decisions related to the purchase of personal goods, as well as the buying of collective goods in the family. Analysis of the family purchasing behavior plays a key role in evaluating market openings, in improving the effectiveness of the marketing strategies, and in expanding distribution as well (Henary,2006). For this reason, and in order to validate the acquired knowledge on the matter, the empirical study proved to be necessary to address our problem.

\section{The empirical study}

In this empirical study, our methodological approach is presented, along with the objectives, sampling method and results.

\subsection{Research methodology}

This study follows a methodological approach similar to several other studies, previously carried out by Davis and Rigaux (1974), and Bonfiled (1978). A list of 09 household appliances was established, namely a refrigerator, stereo, video, television, satellite dish, camera, Playstation games, landline phone, and mobile phone. Most of these products are used by all household members. This collective aspect allows everyone to understand the interactions and influences of family members as regards purchasing. Because it is impossible to organize an exhaustive general survey, a partial survey was carried out. The method or procedure chosen to select the sample is the quota sampling or purposive sampling. The questionnaire was administered in the Wilaya (Province) of Tlemcen (a western Algerian town). The selected sample is composed of 200 households, representing all business sectors, and from all urban and rural communities. The Wilaya of Tlemcen consists of 53 municipalities, resulting from the last administrative division (1984). The sample was distributed in proportion to the total number of households, in each area, as follows: urban area: 112 and rural area: 88 . The information was collected through a questionnaire that was completed by direct interview.

\subsection{Presentation of results}

The interpretation of results of the various qualitative and quantitative analyses is structured as follows. The results, related to the analysis of purchase conduct for a certain category of products, are presented first. Next, the interest expressed by each of the family members towards the various products presented, as well as the distribution and degree of decision-making peculiar to each individual in the household are examined. Finally, the perception of roles in the purchasing process within the household is investigated. 


\subsubsection{The elements of decision making}

The importance of an element of decision-making varies from one person to another, for the same household. Certain elements of decision-making were put together and proposed to the surveyed families. The results obtained are presented in the following table.

\section{Table 1: Elements of decision-making}

\begin{tabular}{c|ccc|ccc}
\multicolumn{2}{c}{ Area } & \multicolumn{3}{c}{ Urban (1) } & \multicolumn{3}{c}{ Rural (2) } \\
\hline \multirow{2}{*}{ Element Person } & Father & Mother & Child & Father & Mother & \multirow{2}{*}{ Child } \\
\hline Prior knowledge & $46.71 \%$ & $10.77 \%$ & $4.38 \%$ & $51.52 \%$ & $6.06 \%$ & $2.09 \%$ \\
Trust a relative & $14.97 \%$ & $42.51 \%$ & $15.57 \%$ & $15.15 \%$ & $24.24 \%$ & $12.12 \%$ \\
Product attributes & $37.78 \%$ & $7.78 \%$ & $18.56 \%$ & $18.18 \%$ & $4.09 \%$ & $9.09 \%$ \\
Emotion & $6.59 \%$ & $11.38 \%$ & $4.79 \%$ & $6.06 \%$ & $36.36 \%$ & $9.09 \%$ \\
Advertisement & $5.39 \%$ & $15.99 \%$ & $12.57 \%$ & $6.06 \%$ & $9.09 \%$ & $9.09 \%$ \\
Seller in a store & $7.78 \%$ & $14.79 \%$ & $24.55 \%$ & $6.06 \%$ & $9.09 \%$ & $21.21 \%$ \\
relevant information on product & $37.19 \%$ & $4.79 \%$ & $4.79 \%$ & $13.27 \%$ & $3.03 \%$ & $3.03 \%$ \\
Price & $52.75 \%$ & $7.78 \%$ & $13.77 \%$ & $42.42 \%$ & $9.09 \%$ & $21.21 \%$ \\
Culture & $4.79 \%$ & $1.80 \%$ & $2.99 \%$ & $9.09 \%$ & $6.06 \%$ & $6.06 \%$ \\
\hline
\end{tabular}

Figure 1: Element of decision-making in urban areas

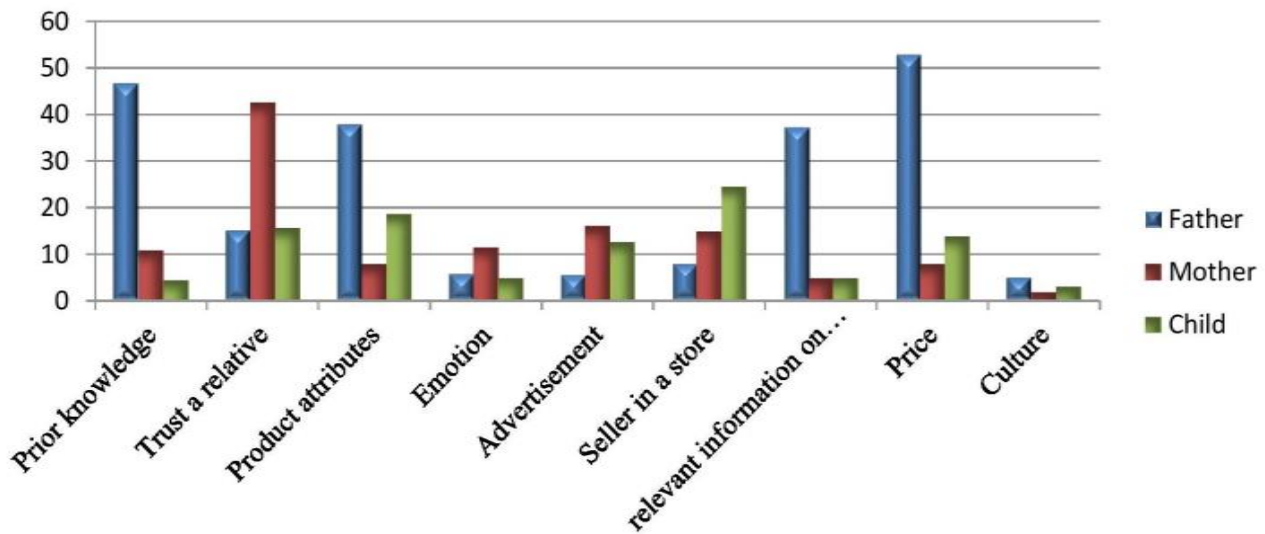

Figure 2: Elements of decision-making in rural areas

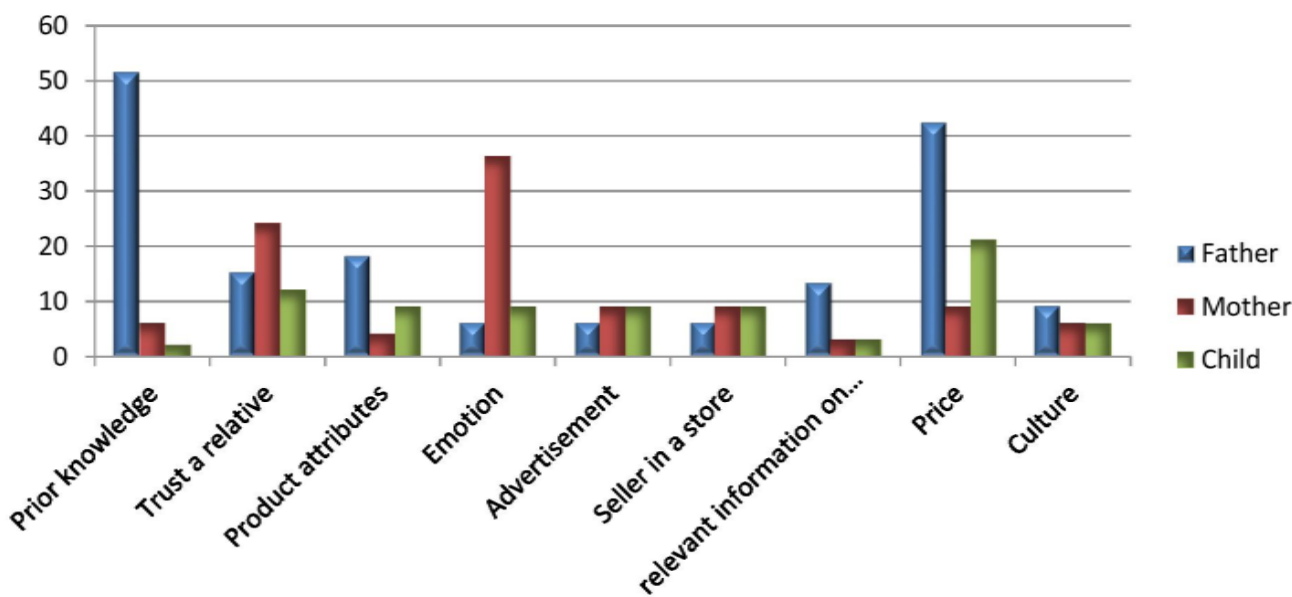


In rural areas, fathers give a particular importance to the price of the product (42.42\%); they often base their choice on lived experience $(51.52 \%)$, by contrast, mothers are more subjective in their choice. They can either be advised by a close relative or friend (24.24\%) or can be influenced by the physical characteristics (design, color, size ...) of the product $(36.36 \%)$. Moreover, children are influenced by vendors $(21.21 \%)$, prices $(21.21 \%)$, and advertising $(90.6 \%)$. Similarly, for urban areas, fathers insist on knowledge (46.71\%) and the financial aspect of the product (52.33\%). In addition, they give great importance to the product attributes $(32.11 \%)$. However, mothers pay more attention to inter-personal elements, such as trusting a relative $(15.57 \%)$ and emotions $(11.38 \%)$. Children are more attentive to product attributes $(18.66 \%)$ and prices $(13.77 \%)$. They are influenced by vendors (24.55\%) and advertising (12.57\%). Price, prior knowledge, product attributes and information are the most important and most considered elements by fathers, but of course with different degrees. In general, mothers prefer to trust relatives; the decision is made in a rather subjective way since they give more importance to emotions and are more influenced by the sellers. Trusting a relative, price and seller's advice represent the most important elements for a child; the other elements have little impact on their choice.

\subsubsection{Degree of involvement}

This study sought to determine the level of involvement of family members and the way family members perceive the product as personally important and relevant. This allows knowing if the interest in the product will increase the participation of the individual in purchasing that product. A household survey, which was conducted in the Wilaya of Tlemcen, allowed us to obtain the results displayed in the following figure:

Figure 3: Degrees of involvement in households, by area.

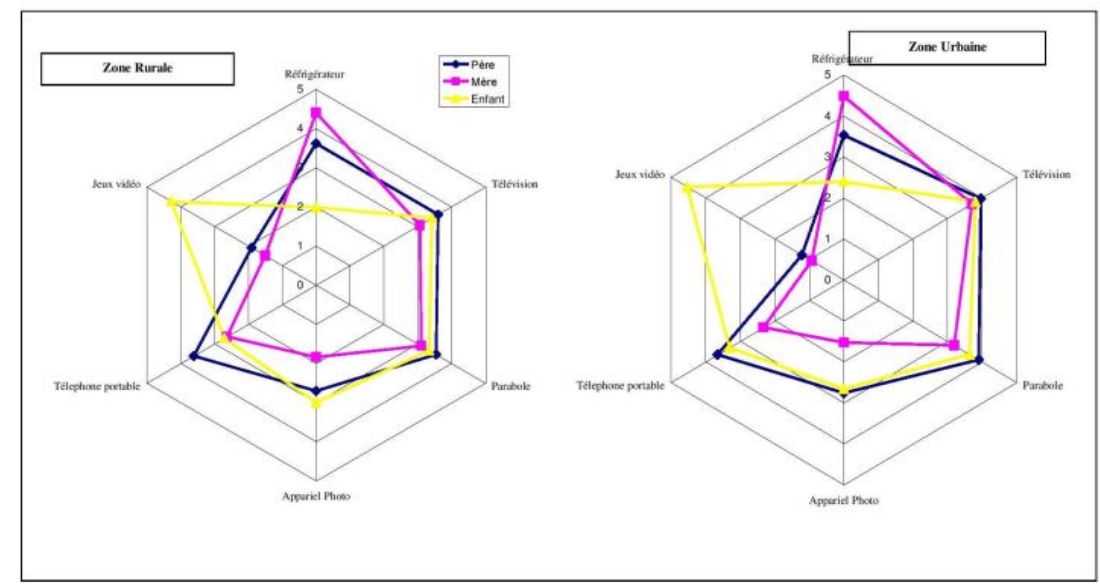

The refrigerator is a product that is interesting most for mothers (more than 4.4 on a five-point scale). For fathers, this number is on the average equal to 3.53 and 3.62 , for urban and rural areas, respectively. Children are the least interested in this product. The television, satellite dish and mobile phone have interest levels that are almost equal for the father, mother and children, in both areas; these levels exceed the value 3 on a five-point scale, for most members. This means that these products are the 
focus of all family members. Children are more attracted to video games, with more than 4 on the same scale, unlike adults who have lower interest in this same product.

\subsubsection{Decision-making at homes}

When one considers measuring participation in family decision-making, he actually thinks about perceptions, i.e. he can either be first to propose the purchase, or to collect information on the purchase or to take the final decision. With regards to household products, if one considers that the purchase depends on the decision of each member of the family, then he must determine the degree of decision-making of each member, and this allows him to know the principal decision maker in the family. The results from the survey concerning purchase decision-making, for all 09 electrical appliances, are shown in Figure 4. A raw measure of the perception of role distribution within the family consists of watching the action frequency of each family member on the basis of the five-point scale in making purchasing decisions for the products previously mentioned.

Figure 4: Levels of decision-making within households, by area.

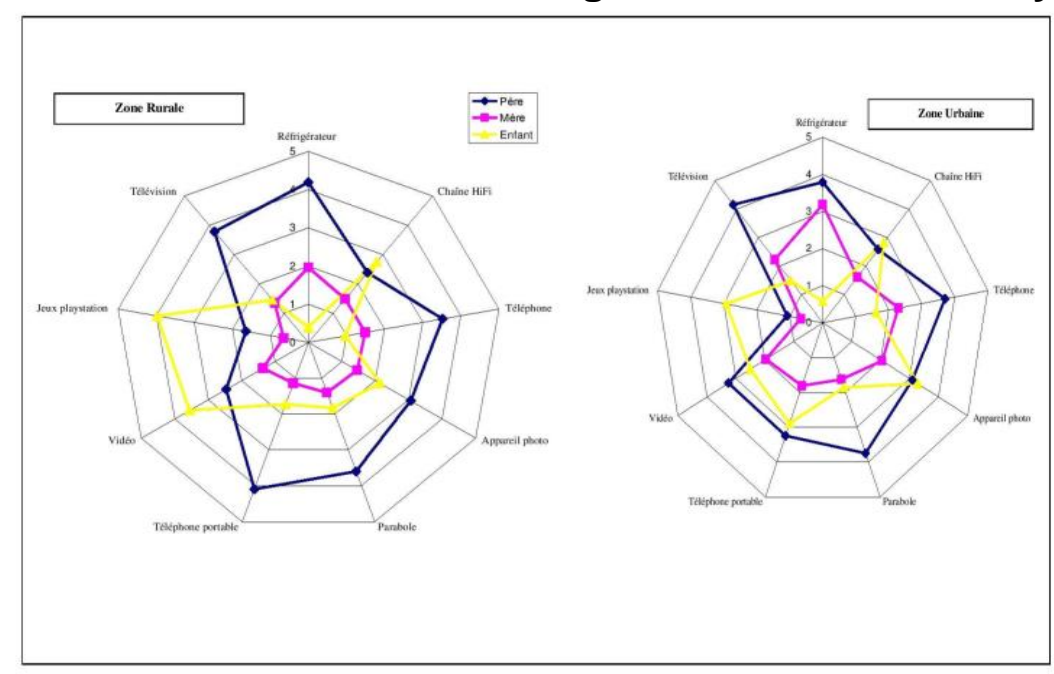

It is noted that the father's participation is greater than that of the other members in the household. The father has a full control on most decisions, except for the stereo and video games, for which higher values of decision making are found for children compared to fathers, in both urban and rural zones. Mothers' participation in decisionmaking must not be neglected. The results show that women do not clearly assert themselves on any decision, but they have a more discreet role in the buying process. This proves that the analysis of the structure of roles, related to purchase in Algerian families, brings up segregation between male and female roles.

Some similarities are noted between the results obtained in this study and those previously reported in the study of Sigue and Duchaine (1998), in Cameroon. The study conducted in Cameroon by the two researchers showed that decision-making is dominated by the father in most cases. The wife's contribution is smaller than that of the husband, but is still significant. The action frequency of children is generally very low, except for some products (toys, school supplies...). 


\subsubsection{Degree of satisfaction based on the choices made in common}

This curve shows that $48.19 \%$ of men and $44.37 \%$ of women are quite satisfied with the purchasing decisions made in common. Also, $33.73 \%$ of men say they are fully satisfied with their choice compared to $19.72 \%$ of women. Note that women (wives) are the least satisfied with the decisions taken in common; this may be due to the stronger participation of men (husbands) in the family income compared to women.

Figure 5: Level of satisfaction of parents at the moment of purchase decision

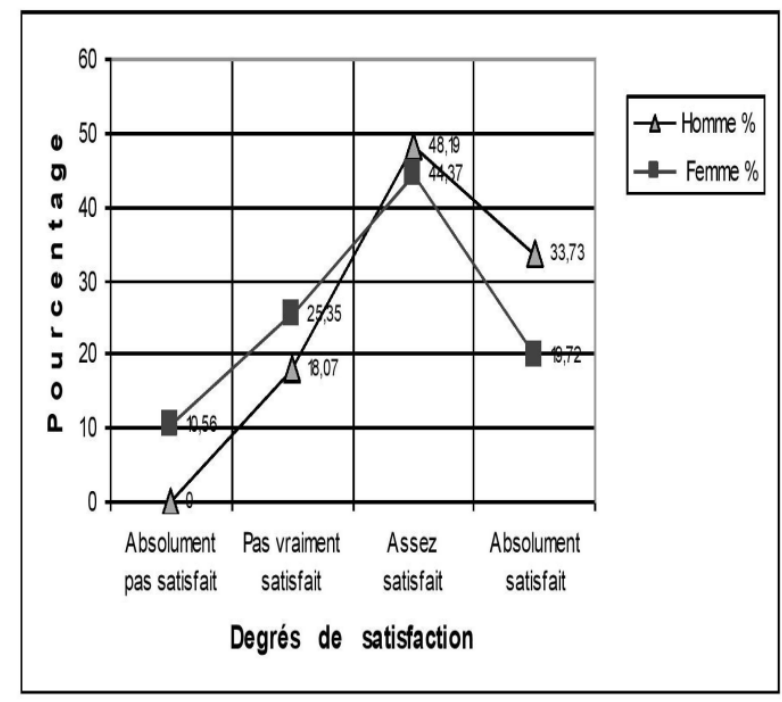

On a scale from -3 (I have got nothing of what I wanted) to +3 (I have got everything of what I wanted), $86.74 \%$ of men and $73.95 \%$ of women say they often get what they want. These percentages may result from vanity, where the respondent overstates his frequency of action as compared to the frequency of action of his spouse, for a given decision. In a related study, Davis and Rigaux (1974) mentioned modesty and vanity.

\subsubsection{Perception of roles in the buying process within households}

Fathers are more concerned and more involved in the family expenses. Overall, the results show that they participate in all stages of the purchase process, and particularly in the final purchase decision. Mothers are less involved financially; they have a rather restricted participation in the process. They have secondary roles; they may prescribe certain products in which they are interested, and can influence their husband to buy them. They do not have a big impact on the final purchase decision of household appliances.

The child's interest is higher for products of a personal character. He is more attracted by recreational or entertainment products such as a stereo system, Playstation games, etc. Children's contribution to household income is low, and therefore, their roles are limited to prescription (suggestion) or search for information. The child is rather an initiator and a user. The results obtained confirm the existence of differences between the socio-professional variables of families surveyed in urban and rural areas; 
however, there are no perceptible differences between urban and rural families, so that one can interpret the role of family members in the purchase process of the products previously mentioned.

\section{Conclusion}

Our research focused on the family purchasing behavior in Algeria, in order to determine the roles of family members in the decision-making process. The results revealed that the influence of family members, especially of parents, varies widely by product type (confirmation of assumption 1). In this study, the perception of family members' roles is examined in regard to the purchase of a category of specific products (household electrical equipment). Buying products of such category is rather complex. Its purchasing process usually goes through different stages, namely problem recognition, search for information, evaluation of alternatives, decision-making. From there, one can see the importance of identifying roles and their interaction, by explaining the family dyad, which is a common purchase decision between members of the same family. The results helped clarify some aspects of purchase of certain appliances. The father was found to have a more decisive and important role in decision-making and financing of the product, given his favorable social and professional status. Roles of initiation and influence, rather secondary but still significant, are played by the mother. The child is more attentive and active in the prescription and research of information about entertainment and leisure products, such as the $\mathrm{Hi} \mathrm{Fi}$ systems and Playstation games.... The perception of roles in the purchase process of household products between the two areas (urban and rural), is probably the same for all phases of the process (rejection of assumption 2).

In conclusion, this area of research is interesting as it provides an opportunity for retail managers to consider the buying habits in the Algerian society to fully adapt their management approach of products, pricing, communication and distribution to their real customers.

\section{References}

[1] Beatty, S.E., \& Talpade, S. (1994). Adolescent influence in family by decision making: A replication with extension. Journal of Marketing Research, 21(2), 332-341. http://dx.doi.org/10.1086/209401

[2] Belch M.A., \& Willis, L.A. (2002). Family decision at the turn of the century: has the changing structure of households impacted the family decision-making process? Journal of Consumer Behaviour, 2(2), 111-124. http://dx.doi.org/10.1002/cb.94

[3] Bonfield, E.H (1978). Perception of Marital Roles in Decision Processes: Replication and Extension » Advances in Consumer Research Vol 5, 300-307.

[4] Cherfi. Sofiane (2011). La culture familiale et la décision d'achat : Cas de la famille française d'origine maghrébine, La Revue des Sciences de Gestion n² 252. 
[5] Davis. H.L \& Rigaux, B.P (1974). Perception of marital roles in Decision processes. Journal of Consumer Research, 1(1), 51-62. http://dx.doi.org/10.1086/208581

[6] Desingly F. (1993) « Sociologie de la famille contemporaine », Nathan, Paris.

[7] Gharbi. J.E, (1998) « Les facteurs qui influencent les processus décisionnels des consommateurs lors d'un achat par Internet » Université de Montréal, p 11.

[9] Henary Assael (2006), Consumer Behaviour and Marketing Action, by Thomson Business Information India Pvt.Ltd.

[10] Houdert, I \& Antonides, G; (1997). Family type effects on household members' decision marketing . Advance in Consumer Research, 24, P.48-54.

[11] Kaur, A. \&Mudury.Y (2010). Children's influence on family purchases: some new insights», Global marketing conferences. Tokyo, Japan, 2010, p.17.

[12] Sigué, S.P \& Duhaime, C (1998), Perception des Rôles Familiaux dans les processus Décisionnels des consommateurs camerounais. International Management, Vol3, NO1, 51-63.

[13] Tammy R. Kinley, Bharath M. Josiam and Fallon Lockett (2010).Shopping behavior and the involvement construct. Journal of Fashion Marketing and ManagementVol.14 No. 4. http://dx.doi.org/10.1108/13612021011081742

[14] Watne, T., \& Brennan, L. (2011). Behavioral change starts in the family: the role of family communication and implications for social marketing. Journal of Nonprofit \& Public Sector marketing, 13(4), 367-386. http://dx.doi.org/10.1080/10495142.2011.623526 